\title{
SECTOR INMOBILIARIO CAPITALISTA Y FORMAS DE APROPIACIÓN DEL SUELO URBANO: EL CASO DE MÉXICO
}

\author{
Martha Schteingart \\ El Colegio de México
}

\section{INTRODUCCIÓN}

EN EL CAPITALISMo dependiente la ciudad constituye un contexto espacial de la acumulación capitalista, pero también, en una medida considerable, de relaciones no capitalistas de producción. Del mismo modo, el marco construido urbano incluye mercancías producidas a través del sector inmobiliario capitalista así como objetos producidos en forma no mercantil, al margen, por lo tanto de dicho sector. ${ }^{1}$

La relación entre la forma de producción de la vivienda en particular, y la inserción de sus usuarios en el sistema productivo es compleja en la medida en que no se puede decir, por ejemplo, que los asalariados integrados al sector capitalista de la economía (o los capitalistas mismos) tengan acceso o consuman objetos inmobiliarios producidos en forma capitalista, mientras aquellos pertenecientes al sector llamado "autónomo" 2 produzcan su vivienda dentro del sistema no mercantilizado.

Ello no es así porque tanto el sector capitalista como el "autónomo" son bastante heterogéneos. Existen en el primero grandes diferencias de remuneración entre los trabajadores pertenecientes a las empresas monopólicas con una elevada composición orgánica del capital y aquellas me-

* Este trabajo constituye un avance de la investigación sobre la ciudad de México que se está realizando en el Centro de Estudios Económicos y Demográficos de El Colegio de México. Se agradece el apoyo financiero del Programa de Investigaciones Sociales sobre Población en América Latina (PISPAL) y del Consejo Nacional de Ciencia y Tecnología (CONACYT),

1 Más adelante se definen las diferentes formas de producción del marco construido urbano y, en particular, el sector inmobiliario capitalista.

2 Aún cuando se considera que este término puede resultar problemático, se ha optado por usarlo en sentido opuesto al concepto de asalariado directamente sujeto a relaciones capitalistas de producción. Cf., Paul Singer "Elementos para una teoría del empleo aplicable a países subdesarrollados", en El empleo en América Latina (varios autores), México, Siglo XXI, 1976. 
dianas y pequeñas, diferencias en el salario directo que también se extienden a subsidios y equipamientos colectivos financiados por el Estado para reproducir la fuerza de trabajo. De esta manera, mientras que los trabajadores mejor remunerados pueden tener acceso a los programas públicos de vivienda o a la vivienda producida a través del sistema inmobiliario capitalista con financiación estatal, el resto (que constituye posiblemente la mayoría en la gran parte de los países latinoamericanos) no tiene otra alternativa que autoconstruir la vivienda o producirla a través de formas artesanales y primitivas.

En el otro extremo, también los representantes del capital prefieren producir su vivienda fuera del sector inmobiliario capitalista, encargando su construcción directamente a pequeñas o medianas empresas. Aún cuando estas empresas pueden ser capitalistas, la forma de producción por encargo que fue la dominante en épocas anteriores, no es mercantil (no existe separación entre producción y consumo; no se produce para el cambio) y por lo tanto no implica en su conjunto, como veremos más adelante, un sistema de producción capitalista.

Por otra parte, el llamado sector "autónomo", comprende en esencia a aquellos que no consiguen vender su fuerza de trabajo, estableciéndose por cuenta propia en el sector terciario (servicios, comercio) o insertándose en sectores productivos decadentes o estancados donde impera un bajo índice de capitalización (producción artesanal, industria a domicilio).

Estos trabajadores que constituyen el subproletariado urbano, también autoconstruyen, en general, su vivienda, o bien utilizan trabajo asalariado para producir un valor de uso con condiciones mínimas de habitabilidad.

Pero también pertenecen a este sector "autónomo" algunos trabajadores por cuenta propia (profesionales por ejemplo), que obtienen un nivel de remuneración que les permite tener acceso a la vivienda producida dentro del sistema inmobiliario capitalista. Estos grupos son minoritarios y en general tienden a decrecer.

Si bien no tenemos información precisa con respecto al número de viviendas producidas a través de los diferentes sistemas, es posible afirmar que predomina en el capitalismo dependiente aquélla perteneciente al sistema no mercantilizado.

Por ejemplo, en México, el $65 \%$ de las familias no tienen acceso a las viviendas producidas en forma capitalista con financiamiento privado o público, debiendo en consecuencia autofinanciar y en gran medida autoconstruir su vivienda. ${ }^{3}$

De esta manera, la producción del marco construido habitacional se $\mathrm{da}$, para las grandes mayorías urbanas, al margen del sistema inmobiliario

3 G. Garza y M. Schteingart, La acción habitacional del Estado en México, El Colegio de México, 1978. 
capitalista, constituyendo las llamadas colonias proletarias o ciudades perdidas, donde predomina la tenencia ilegal de la tierra, la falta de servicios y la vivienda autoconstruida, en condiciones de gran precariedad.

Es necesario aclarar que la autoconstrucción (junto a otros tipos de autoabastecimiento individual o colectivo) forma parte, como ya se dijo, de las prácticas de consumo que desarrolla gran parte del proletariado urbano frente a la escasez de los salarios, en los cuales no se reconocen sino de manera mínima y parcial las necesidades de la reproducción de la fuerza de trabajo. La autoconstrucción, como otras formas de trabajo doméstico, disminuye el valor de cambio de la fuerza de trabajo y aumenta la tasa de plusvalía extraída en la producción capitalista. ${ }^{4}$

También resulta importante señalar que en esos asentamientos populares, producidos fuera del sistema inmobiliario capitalista, están presentes, no obstante, sectores que valorizan su capital, como los productores de materiales, los fraccionadores y los urbanizadores. Estos últimos intervienen sobre todo cuando el Estado regulariza la tenencia de la tierra e instala servicios, que en última instancia son pagados por los usuarios.

En cuanto a la producción no mercantil, para estratos de altos ingresos que prefieren producir su vivienda por encargo, ella debe ser seguramente minoritaria. También existe este tipo de producción para sectores medios, sobre todo en las pequeñas ciudades; no se conoce el número de unidades construidas a través de este sistema, pero es evidente que en la ciudad de México está declinado. El apoyo crediticio a la vivienda realizada en forma individual es mínimo y, como se verá más adelante, la disminución del sistema de fraccionamiento con venta de lotes solos y el avance de la promoción inmobiliaria constituyen un índice de esa declinación.

El predominio de formas no capitalistas de producción de la vivienda, y sobre todo la existencia de sectores mayoritarios de la población que habitan en colonias proletarias o ciudades perdidas, ha inducido a muchos investigadores latinoamericanos a centrarse en el análisis de estos asentamientos precarios y de las formas de producción del medio construido que ellos implican.

Sin embargo, se considera que la existencia y condiciones en que se dan estos fenómenos, no pueden ser explicados si se ignora el funcionamiento del sector inmobiliario y sus efectos sobre la acumulación de capital y la reproducción de la fuerza de trabajo, en el marco particular de formaciones sociales marcadas por grandes desequilibrios entre clases y grupos sociales o, de manera más específica, por la existencia de un enorme "ejército industrial de reserva".

Por otro lado, tampoco es posible, sin el análisis de ese sector, comprender el sentido y alcances reales de las políticas habitacionales del estado, uno de cuyos objetivos básicos es justamente actuar sobre las con-

4 Christian Topalov, La urbanización capitalista. Algunos elementos para su análisis, México, Edicol, 1979. 
diciones de valorización del capital privado en la producción y circulación de la vivienda.

Es importante tener en cuenta que aún cuando un sector productivo desarrollado no sea en apariencia dominante en la sociedad, puede fijar condiciones que alteren o incidan en el funcionamiento de aquellos menos desarrollados, ya sean resabios de modos de producción anteriores o nuevas formas de los mismos. Por ejemplo, la producción no capitalista de la vivienda o la autoconstrucción tendrían que pagar su tributo al mercado capitalista del suelo urbano (que ha comenzado a desarrollarse con el avance del sistema inmobiliario capitalista), como consecuencia de los probables usos capitalistas que podría tener el suelo sobre el cual esa producción se apoya.

Las reflexiones precedentes han inducido a comenzar el análisis del sector inmobiliario capitalista en un país como México, aún cuando se tiene conciencia de que las viviendas producidas por el mismo están dirigidas a un sector minoritario de la sociedad.

\section{EL DESARROLLO DEL SECTOR INMOBILIARIO CAPITALISTA EN MÉxICO (ALGUNOS AVANCES DE UNA INVESTIGACIÓN EN CURSO)}

\section{Antecedentes y marco teórico del estudio}

La falta de antecedentes en la investigación de la estructura interna y comportamiento del sector inmobiliario capitalista, así como de sus efectos en la producción de la vivienda para los diferentes sectores sociales en América Latina ha llevado a buscar apoyo, para el desarrollo del marco teórico de este estudio, en los rigurosos trabajos que sobre ese tema se han realizado de manera particular para Francia. ${ }^{5}$

Si bien la situación descrita para el capitalismo desarrollado, tanto en su etapa actual como en su proceso histórico, puede diferir de la nuestra, se considera que tanto la metodología empleada como ciertos aspectos teóricos básicos en los que se apoyan esos estudios pueden resultar válidos para orientar un análisis de la realidad latinoamericana en este campo.

Los estudios mencionados parten de la identificación de los sistemas de producción y circulación de la vivienda que se han sucedido en las diferentes etapas del desarrollo de la sociedad (sobre todo en el capitalismo) así como de aquellos sistemas que coexisten en un momento dado Ese análisis implica la consideración de las funciones de los agentes que intervienen en el sector y de las relaciones sociales que lo organizan, vis-

5 Los estudios desarrollados sobre todo por Ch. Topalov sobre la promoción inmobiliaria, publicados en su libro: Les promoteurs inmobiliers. Contribution a l'analyse de la production capitaliste du logement en France, Mouton, 1974; véase también, Ch. Topalov, La urbanización capitalista, op. cit. 
tas en el marco de las relaciones de clase que se dan en el conjunto de la sociedad. En este contexto, se observa que la promoción inmobiliaria constituye el sistema capitalista más avanzado que domina en la actualidad la producción de viviendas en países capitalistas desarrollados. Este sistema, que coexiste con otras formas de producción que tienden a retroceder, supone entonces la destrucción o marginación de sistemas anteriores, como el suministro no mercantilizado de la vivienda que ya se ha mencionado (producción de vivienda como valor de uso) y de lo que se ha dado en llamar "sistema de valorización de la propiedad del suelo". Éste presupone la transformación de la vivienda en mecancía y en capital y se basa en la transformación del propietario del suelo en capitalista inmobiliario. Cuando aparece la demanda de vivienda, sobre todo para los sectores asalariados, los propietarios del suelo, si disponen de capital-dinero, están en condiciones de valorizar en forma capitalista su propiedad al construir viviendas que alquilan a los asalariados o venden a capitalistas que van a cumplir la función de rentistas inmobiliarios. Si esos propietarios no disponen de recursos suficientes pueden acondicionar el terreno y venderlo en parcelas. Este sistema de fraccionamiento, considerado como de transición entre el anterior y la promoción inmobiliaria, permitiría superar, en cierta medida, la limitación en la producción de vivienda que surge de la determinación del volumen de esa producción por la propiedad del suelo (ésta quedaría limitada por el capital-dinero dísponible por los estratos sociales que son propietarios del suelo). En el fraccionamiento, el propietario ya no es capitalista rentista inmobiliario; serán los constructores quienes van a financiar la producción y asegurar la circulación de las vivien. das. Por lo tanto aquél sólo se apropiará de la renta del suelo, renunciando a la renta inmobiliaria. Este sistema de transición presenta entonces un principio de ruptura de la unidad del capital y la propiedad territorial que caracterizaba al sistema llamado de "valorización de la propiedad del suelo".

Los análisis que serán realizados para México podrán mostrar de qué manera ocurren esos cambios en el capitalismo dependiente y en qué medida se aplican los sistemas de transición descritos en los estudios mencionados.

En cambio, desde el punto de vista conceptual, es importante recoger la definición que aquéllos presentan del sistema de la promoción inmobiliaria. Este aparece cuando el capital inmobiliario es autónomo en relación a la propiedad del suelo; con él se presenta también el mercado capitalista del suelo y el antagonismo entre el capital y la propiedad por la repartición de la renta. Mientras en los sistemas anteriores el propietario capitalista inmobiliario controla el momento de cambio del uso del suelo beneficiándose de la parte fundamental de la renta, con la promoción inmobiliaria el capital inmobiliario debe liberar un terreno para or- 
ganizar el cambio de uso del suelo, desplazando al propietario en la apropiación esencial de las sobreganancias localizadas. ${ }^{6}$

Por otro lado, para poder explicar los cambios en los sistemas de producción capitalista de la vivienda, así como las características de la promoción inmobiliaria, es necesario conocer las especificidades estructurales del sector inmobiliario en relación con otros sectores de la producción capitalista, a partir justamente del análisis de las relaciones de producción que se dan en el mismo, es decir del capital.

La producción de objetos inmobiliarios encuentra problemas específicos en relación a la renovación del ciclo del capital, ellos se dan tanto en la reproducción de las condiciones de producción como en la realización del valor.

El obstáculo fundamental que encuentra la reproducción de las condiciones de producción es que en el caso de la producción inmobiliaria, a diferencia de otros sectores, es necesario un nuevo suelo soporte para cada proceso productivo, y el suelo no es reproductible por el capital, no es una mercancía, y además es monopolizable.

De esta manera, la renovación de cada ciclo de capital va a depender de la eliminación del obstáculo suelo, y el capital-dinero inicial del ciclo debe pagar además de los medios de producción y la fuerza de trabajo, la renta del suelo. Estas características especiales del ciclo generan la aparición de una fracción especializada del capital, autónomo del capital industrial: el capital de promoción.

Este libera al terreno para destinarlo a un nuevo uso y hace posible la producción sobre el mismo; proporciona a las empresas constructoras el apoyo para la producción, asegurando el pago de los trabajos a medida que avanza la obra. Al prefinanciar la construcción el capital de promoción interviene como un capital de circulación que acelera la rotación del capital industrial.

La ganancia de promoción está constituida entonces, en parte, por la ganancia media del capital que paga la construcción pero, al mismo tiempo, al organizar la producción el capital de promoción conduce a la formación de sobreganancias localizadas, siendo luego la renta un segundo componente, muy importante, de la ganancia de promoción. La rentabilidad de la operación inmobiliaria depende de una combinación de capitales; ella se financia con el capital de promoción, el capital de préstamo, que sustituye en parte al capital de promoción, y con el pago de los usuarios (que comienzan a aportar desde el principio de la obra ya que es desde entonces que en general pueden iniciarse las ventas). Para compren-

6 Las rentas del suelo constituyen una transformación de sobreganancias localizadas, originadas por la valorización del capital. Esas sobreganancias escapan al proceso de nivelación de la ganancia y se fijan como rentas del suelo. De acuerdo con las relaciones de producción imperantes ellas tomarán las formas de precio del suelo, sobreganancias de promoción, etc. y se distribuirán entre los diferentes agentes sociales. 
der la lógica económica de los promotores inmobiliarios no es suficiente conocer el valor absoluto de la ganancia de promoción; la velocidad de comercialización y la combinación de capitales constituyen elementos fundamentales para analizar la tasa de ganancia.

Como se mencionó, la segunda especificidad del sector inmobiliario se da en relación a la realización del valor y consiste en la duración excepcional del período de circulación de la mercancía (transformación del capital-mercancía en capital-dinero). Ello se debe a la inadecuación de los precios con respecto a los ingresos, que es mucho mayor que en otras mercancías. "El asalariado sólo puede pagar su vivienda a medida que la consume."

Esta situación hace necesaria la aparición de una nueva fracción de capital: el capital de circulación, que se inmoviliza durante el periodo necesario para que los usuarios cancelen el precio del inmueble. Su existencia es una condición para la misma producción. Este capital de circulación va a tomar dos formas: el capital inmobiliario rentista y el capital de préstamo, cuyo peso variaría en las diferentes etapas del capitalismo.

El nacimiento del crédito inmobiliario es contemporáneo de la aparición de las primeras formas de producción capitalista de la vivienda, pero se produce un cambio importante cuando el capital de préstamo pasa a financiar la adquisición de viviendas por los mismos ocupantes. Ello sólo es posible, sobre todo para el caso de los sectores mayoritarios de la sociedad, cuando el capital de préstamo es un capital desvalorizado (que implica una reducción de las altas tasas de interés); esta desvalorización es posible gracias a la intervención directa o indirecta del Estado en el financiamiento.

Por último, las características particulares del sector inmobiliario tienen consecuencias sobre la producción misma, es decir sobre la industria de la construcción; si bien ésta se expande con un aumento considerable del desarrollo de las fuerzas productivas y relaciones de producción capitalistas, ese desarrollo es relativamente menos avanzado que en otras ramas de la producción. Se hipotetiza que la propiedad del suelo y la renta urbana son la base del bloqueo al desarrollo de las fuerzas productivas dentro del sector.

\section{Presentación de la investigación}

En el Colegio de México se está desarrollando una investigación sobre el sector inmobiliario capitalista como parte de un estudio más amplio sobre la estructura económica y la producción del espacio en el Área Metropolitana de la Ciudad de México.?

7 Este proyecto está constituido por dos partes: una a cargo de Gustavo Garza se refiere a la estructura económica del Área Metropolitana y la otra a cargo de la autora de este trabajo, se refiere al proceso de producción del 
En concordancia con el marco teórico esbozado, los objetivos de ese estudio son conocer básicamente la estructura interna y comportamiento de ese sector así como sus efectos sobre la reproducción de la fuerza de trabajo y las formas de apropiación del espacio en la Ciudad de México. En particular, cómo el funcionamiento de este sector incide sobre el del mercado del suelo urbano y sobre la formación y expansión de los "asentamientos populares".

Para el logro de esos objetivos se ha considerado necesario estudiar la lógica de acción de los diferentes agentes que intervienen dentro del sistema, qué relaciones se dan entre los mismos, qué transformaciones se han operado al interior de ese sistema como consecuencia de la creciente intervención del Estado y, de manera más específica, detectar la importancia de los diferentes tipos de promotores privados, su vinculación con el capital financiero y con el Estado, así como sús modos concretos de operación.

El conocimiento de los problemas y aspectos mencionados se basa de manera principal en la información obtenida de una encuesta que se está aplicando a los agentes más importantes que han intervenido en el proceso de producción y circulación de la vivienda, correspondiente a una muestra representativa de operaciones inmobiliarias realizadas en el Área Metropolitana desde principios de los años sesentas hasta la fecha.

Esta muestra incluye operaciones de diferentes tamaños, localizadas en diversos sectores del Área Metropolitana, comenzadas en distintas etapas del periodo en estudio y con diferentes tipos de financiación (público, privado y mixto). También se han incorporado a la muestra operaciones promovidas por el sector público con el objeto de completar el cuadro relativo a las combinaciones posibles entre el sector público y el privado. Se ha partido de la premisa de que existen lógicas distintas de valorización del capital de promoción en los fraccionamientos y en los conjuntos habitacionales, ${ }^{8}$ razón que ha llevado a considerarlos como dos universos separados. Por otro lado, la localización ha sido considerada una variable de mayor importancia que las demás, en la medida que permite analizar el problema de la relación entre promoción y propiedad del suelo, así como precisar de qué manera se forma uno de los componentes esenciales de la ganancia de promoción (la renta). Este problema será analizado, además, a través de información complementaria a la que se obtendrá de la encues-

espacio. El estudio sobre el sector inmobiliario capitalista que aquí se presenta complementa otros ańlisis sobre el Área Metropolitana, referidos de manera fundamental a la tierra urbana (formas de tenencia, expropiaciones, precios del suelo) así como a las formas particulares de apropiación del suelo en áreas populares.

8 Llamamos fraccionamientos, en un sentido amplio, a las operaciones que incluyen tanto la venta de tierra urbanizada como la de lotes con vivienda individual, y conjuntos habitacionales a las operaciones que incluyen un conjunto de edificios de vivienda de carácter colectivo. 
ta (análisis de valores del suelo; consulta al registro público de la propiedad).

Las entrevistas a promotores privados, empresas constructoras, agentes de comercialización, representantes del capital financiero y de los organismos públicos de vivienda, permitirán, por un lado, conocer las características de esas empresas e instituciones en cuanto a su origen, importancia, organización interna y vinculaciones con otras empresas o grupos económicos, y por otro, detectar la lógica de las operaciones realizadas, sobre todo en cuanto a la formación de la tasa de la ganancia de promoción. Para ello es necesario conocer con detalle la secuencia de las actividades involucradas, los desembolsos que ellas implican en el tiempo y los ingresos recibidos como consecuencia de la combinación del capital de promoción con el capital de préstamo, articulados al ritmo de la comercialización.

Si bien esta investigación está aún en proceso y no se tienen, por lo tanto conclusiones definitivas, se ha considerado que podría tener interés presentar algunos avances de la misma, como base para una discusión de esta problemática de análisis, casi inexplorada en América Latina. Esta discusión podría quizás orientar la realización de estudios comparativos sobre el tema.

\section{Algunos resultados de la investigación}

\section{Antecedentes}

La investigación que se está llevando a cabo sólo permitirá conocer las características del sector inmobiliario capitalista en la etapa más reciente de desarrollo del capitalismo en México, y examinar su evolución en los ûltimos 15 años. Como no existen estudios históricos que permitan conocer en detalle cuáles han sido las formas de producción de la vivienda que se han sucedido o coexistido en etapas anteriores, resulta imposible afirmar si se aplican a México los esquemas presentados, por ejemplo, para algunos países europeos.

Sin embargo, se puede hipotetizar que no puede existir una gran coincidencia en cuanto a la generación y evolución de esas formas de producción, teniendo en cuenta las notables diferencias que pueden observarse en el desarrollo histórico de las sociedades hoy altamente desarrolladas y las pertenecientes al capitalismo dependiente. Estas diferencias resultan evidentes en la evolución más reciente como el caso del sistema de fraccionamiento, que se discute más adelante.

El sistema capitalista más avanzado de producción de viviendas, la promoción inmobiliaria, empieza a desarrollarse en México sobre todo en los comienzos del decenio de 1960, gracias a los cambios ocurridos en las mo- 
dalidades operativas del crédito hipotecario, a la expansión del mismo y a la intervención del Estado en el financiamiento de la vivienda.

Si bien el gran crecimiento de la ciudad de México se acelera al comienzo de los años cuarenta, y por lo tanto la demanda de vivienda para los sectores asalariados (que se incrementan con el desarrollo industrial del país) parecería ser que en los decenios de 1940 y 1950 esas demandas son en parte satisfechas para los sectores medios a través del sistema del fraccionamiento (vinculado a la producción no mercantil o bien a la producción mercantil de pequeñas operaciones sin intervención de promotores), o de la acción directa del Estado que se lleva a cabo sobre todo para empleados del sector público. Los estratos de menores ingresos, que como ya se dijo antes, nunca han tenido acceso al sistema de promoción inmobiliaria, en esta época probablemente se seguían hacinando en las vecindades centrales, formaban colonias proletarias, sobre todo en las zonas periféricas del Distrito Federal o comenzaban a asentarse en fraccionamientos ilegales en el Estado de México.

\section{La promoción inmobiliaria vinculada a los fraccionamientos}

Se puede diferenciar, para el caso del Área Metropolitana de la Ciudad de México," la promoción inmobiliaria ligada a los fraccionamientos, que se da sobre todo en los municipios del Estado de México y aquélla aplicada a conjuntos habitacionales de vivienda colectiva que se presentan en el Distrito Federal. En este último los fraccionamientos estuvieron prohibidos durante muchos años para evitar el crecimiento de la ciudad y aún hoy resulta muy difícil conseguir un permiso para fraccionar. Ello impulsó el gran desarrollo de los fraccionamientos en el Estado de México, el cual acompañó, por otra parte, la enorme expansión metropolitana en esta zona, que se acentúa notablemente durante el decenio 1960-1970.

Los fraccionamientos habitacionales aprobados entre 1960 y 1977 en los municipios del Estado de México que forman parte del Área Metropolitana ascienden a 190, con una superficie aproximada de 9000 hectáreas que incluye unos 292500 lotes. ${ }^{10} \mathrm{Si}$ bien los fraccionamientos aparecen

- El Área Metropolitana de la ciudad de México abarca actualmente una parte del territorio del Distrito Federal y se expande hacia el norte, sobre varios municipios del Estado de México. El crecimiento de la ciudad se produjo entre 1940 y 1950 casi en exclusiva dentro de los límites del Distrito Federal, comenzando posteriormente la expansión sobre el Estado de México. Los municipios de ese estado que se incorporan al Area Metropolitana pasan de uno en 1950 con 29144 habitantes, a once en 1970 , con 1907700 y tasas medias de crecimiento anual que van en aumento hasta alcanzar en $1960-1970$ una tasa de $74.6 \%$.

10 Estos datos han sido elaborados a partir de la relación de fraccionamientos autorizados por el gobierno del Estado de México de 1960 a 1977. Información provista por la Dirección de Comunicaciones y Obras Públicas a través del Departamento de Control y Supervisión de Fraccionamientos (Toluca-México). 
mayoritariamente ( $80 \%$ de los lotes) como populares, de acuerdo a la calificación de la ley de fraccionamientos del Estado de México en cuanto a tamaño de los lotes y otras características, ello no implica que en la realidad estén destinados a estratos de menores ingresos (se ha comprobado que se producen también en ellos viviendas de alto costo, o por lo menos no de "interés social").

Estos fraccionamientos se concentran casi en un $60 \%$ en tres municipios, los más cercanos al Distrito Federal, notándose asimismo grandes diferencias en los tamaños de los mismos por municipio (desde un tamaño medio de 413 lotes por fraccionamiento en Naucalpan a 3600 en Coacalco y 2600 en Ecatepec).

Por otro lado, se puede observar que el $33 \%$ de los fraccionamientos tienen entre 100 y 500 lotes, el $35 \%$ entre 500 y 2000 y sólo el $9 \%$ más de 5000 lotes. Esto indica que predominan, por un lado, las pequeñas y medianas operaciones, mientras que 17 grandes fraccionamientos concentran casi el $30 \%$ del total de la superficie ocupada por el conjunto de las mismas.

Si bien no se conocen cuáles han sido las proporciones de lotes vendidos con y sin vivienda, es posible hipotetizar, sin embargo, que a partir de los años sesentas avanza la promoción inmobiliaria y retrocede al mismo tiempo la venta de lotes sin vivienda, que constituía, sobre todo en los años cincuenta, la única alternativa; ella se vinculaba tanto a la autoconstrucción (en el caso por ejemplo de fraccionamientos populares e ilegales como Nezahualcóyotl) como a la producción por encargo em. pleando empresas constructoras.

Por ejemplo, en el caso de los grandes fraccionamientos, se ha podido comprobar, a través de la encuesta, que un $70 \%$ de los lotes se venden con vivienda. Los fraccionamientos pequeños, en cambio, combinan en menor medida la promoción inmobiliaria con la venta de lotes solos (en general se venden o bien todos los lotes con vivienda o bien todos los lotes sólo con su urbanización).

a) Las empresas promotoras de grandes fraccionamientos. Es posible avanzar algunas conclusiones en relación a los grandes fraccionamientos ya que la encuesta se ha dirigido por el momento a los agentes que intervinieron en la producción y comercialización de los más importantes.

De los 17 fraccionamientos que tienen más de 5000 lotes, cuatro han sido promovidos por el Estado a través de sus instituciones especializadas (BANOPSA-INDECO-INFONAVIT). El resto de las operaciones fueron realizadas por nueve grupos promotores privados, dos de los cuales manejan una gran cantidad de fraccionamientos (sin embargo, uno de ellos ha sido integrado a una empresa con participación estatal debido a sus problemas financieros) y los demás, sólo dos o tres grandes operaciones. Algunos de estos grupos empresarios tienen vinculaciones a través de sus socios. En general, cada grupo está formado por varias empresas (tres o cuatro en 
el caso de los menores y hasta más de 100 en el caso de la más importante). Las causas de esta diversificación empresaría son variadas: reducción de tasas de impuestos; necesidad de descentralizar el manejo administrativo de las operaciones; la lógica misma de los negocios que lleva a producir diferentes tipos de asociaciones entre acciónistas y también, en algunos casos, la necesidad de crear empresas fantasmas para la obtención de créditos o para crear una cobertura jurídica en relación a los consumidores. Vemos, entonces, cómo esa diversificación, que también se presenta en otros sectores productivos, tiene algunas especificidades en el caso del sector inmobiliario. Ella responde, en última instancia, al objetivo de aumentar la tasa de ganancia de promoción y por lo tanto la acumulación de capital, basándose tanto en la optimización de la gestión de las operaciones como en el fraude y engaño, con una fachada de legalidad, a los consumidores, otros agentes del sistema y al Estado.

Se ha podido comprobar que en algunos casos el capital inicial de las empresas (capital de promoción) proviene de la industria, sobre todo textil, mientras en el caso del grupo más importante se trata de capitales originados en operaciones inmobiliarias (fraccionamientos en el Distrito $\mathrm{Fe}$ deral, iniciados hace varios decenios).

b) La lógica de las grandes operaciones. En cuanto al desarrollo de estas grandes operaciones, se da en general una gran variedad de situaciones al interior de las mismas en relación a la comercialización de los lotes y al financiamiento de las promociones. Estas variaciones responden a la necesidad de diversificar el mercado, a las posibilidades crediticias y a la lógica de valorización de la tierra. Así por ejemplo, en una misma operación se puede presentar la venta de lotes solos en forma individual, o en bloque a otros promotores (en general pequeños) para que construyan las viviendas. La venta de lotes con casas por medio de financiación bancaria (ya sea con créditos de interés social o créditos hipotecarios para sectores de altos ingresos) y, por último, la venta de lotes con casa, en bloque, a organismos públicos (sobre todo INFONAvir). Esta última forma se ha desarrollado de manera principal en los últimos años y ha permitido que los promotores continuaran sus operaciones, a pesar de la gran declinación del crédito hipotecario que se ha dado después de la crisis económica producida hacia el final de la administración pasada (fines de 1976). Este constituye un claro ejemplo de apoyo del Estado a la acumulación capitalista en el sector inmobiliario (financiación de la demanda por medio del capital público desvalorizado).

Se puede decir que en los casos analizados el capital inicial de las empresas, necesario para adquirir el terreno; pagar los estudios técnicos y los permisos o autorizaciones, es relativamente reducido en relación al monto total de las operaciones. Sin embargo, en los últimos años el costo de los permisos ha aumentado notablemente y generado serias protestas por parte de los promotores. Además, el capital puede combinarse en esta primera 
etapa con el capital de préstamo a corto piazo, tanto de bancos nacionales como norteamericanos, ya sea para financiar parte de los gastos mencionados como también, en algunos casos, los costos de la urbanización.

En otros casos estudiados; la urbanización fue financiada por las mismas empresas urbanizadoras.

c) El capital inmobiliario y la propiedad del suelo. En cuanto a la obtención de los terrenos, los promotores pueden asociarse a veces con los propietarios, para no tener que realizar grandes desembolsos iniciales en la compra de los mismos. Ello depende de los recursos de que disponga el promotor, del costo de los terrenos y también de quién sea el propietario. La asociación con altos funcionarios públicos dueños de la tierra puede proveer numerosas ventajas, sobre todo en relación a la obtención de autorizaciones, créditos, etc.

En algunos de los grandes fraccionamientos analizados los terrenos tuvieron un costo inicial muy bajo ya que se encontraban en zonas muy periféricas y poco desarrolladas, pero su valorización fue muy rápida (el precio por metro cuadrado aumentó aproximadamente cinco veces en seis años) gracias al gran crecimiento del Área Metropolitana sobre el Estado de México, permitiendo enormes ganancias a los promotores.

También en estos casos se ha observado un largo período (seis a siete años) de espera entre el momento de la compra de los terrenos y el comienzo de la operación, período en el cual la tierra se valorizó sin que el promotor tuviera que realizar ninguna inversión en capital-dinero, apropiándose así de las rentas diferenciales generadas por el propio desarrollo urbano.

Se podría decir que la compra anticipada de la tierra constituye una operación de tipo especulativo que tiene por objeto moderar, en cierta medida, el obstáculo que opone la tierra a la acumulación de capital.

De manera evidente, el manejo de la tierra se vuelve, en el caso de los fraccionamientos, un elemento fundamental en la formación de la ganancia de promoción. Al parecer, las grandes empresas fraccionadoras y promotoras tienen una posición de fuerza que les permite obtener tierra barata a través de diferentes mecanismos, entre los cuales se cuentan las presiones a pequeños propietarios e incluso la apropiación ilegal de tierra de carácter público.

En este sentido es importante hacer notar que el crecimiento del Área Metropolitana sobre el Estado de México se ha producido en un $21.8 \%$ sobre tierra ejidal, en un $27.7 \%$ sobre tierra comunal, en un $27.7 \%$ sobre tierra estatal y sólo un $22.7 \%$ sobre tierra de carácter privado. Es decir que ella ha crecido en un $77.2 \%$ sobre tierra de carácter público.

Sobre todo en los municipios de Naucalpan y Tlalnepantla, que concentran una alta proporción de fraccionamientos, la proporción de tierras ejidales es muy alta ( 68 y $40 \%$, respectivamente). 
Por otro lado, se ha podido comprobar, al analizar a qué usos urbanos se ha destinado la tierra de carácter público, que los terrenos ejidales fueron ocupados en un $41 \%$ por vivienda de tipo residencial, para estratos de altos ingresos. ${ }^{11}$ No se conoce a través de qué mecanismos esa tierra fue transformada a usos urbanos incompatibles con lo fijado por la Ley de Reforma Agraria, pero todo esto indica que es probable que una parte importante de los fraccionamientos se haya desarrollado sobre terrenos ejidales.

A veces los organismos públicos (AURIS, por ejemplo) han servido como intermediarios en la apropiación por el capital de terrenos de carácter público, al expropiar ejidos y promover en ellos fraccionamientos que luego eran vendidos a las empresas promotoras capitalistas.

d) El pre-financiamiento de la construcción. En general, la construcción de la vivienda es financiada por los créditos hipotecarios con tasas "normales" de interés, para sectores de altos ingresos, o bien por créditos de interés social, que presentan tasas más reducidas, un período más largo de amortización de la deuda, cubriendo asimismo una mayor proporción del costo de la vivienda. ${ }^{12}$

Como ya se dijo, en los últimos años se ha agregado a los créditos hipotecarios la financiación con capital público desvalorizado de organismos como INFONAVIT, y en menor medida del FovissSTE.

No se dispone de información precisa que permita conocer las proporciones de viviendas realizadas con créditos de interés social y créditos hipotecarios con altas tasas de interés, pero es posible suponer que los primeros han sido minoritarios (sólo se dieron 32800 créditos de interés social entre 1964 y 1977 en el Estado de México —datos del Fovi).

11 Estos datos provienen de un estudio referido al crecimiento de la ciudad de México sobre distintos tipos de tenencia de tierra rural (forma parte del citado proyecto de investigación que se lleva a cabo en El Colegio de México). La tierra comunal tiene sus origenes en la época prehispánica; los españoles la mantuvieron en parte durante la Colonia y ha seguido existiendo hasta la fecha con una organización similar a la de las comunidades prehispánicas. La tierra ejidal se entrega a los campesinos en usufructo pero no puede enajenarse; sólo puede ser expropiada según la Ley de Reforma Agraria que la rige, para usos de carácter público o interés social.

12 En 1963 se crea en México el Programa Financiero de la Vivienda (PFv), a través del cual el Estado exige que los bancos destinen un 30\% de los recursos de sus departamentos de ahorro a vivienda de interés social. Estos créditos con tasas de interés de $10 \%$ cubren el $80 \%$ del costo de la vivienda y se entregan para la construcción o adquisición de viviendas que cumplan con las normas establecidas por el Fovi (Fondo de la Vivienda) para las llamadas viviendas de interés social cuyo precio máximo no puede superar ciertos topes fijados por ese fondo. Estos precios máximos han ido variando con el tiempo, habiéndose realizado recientemente un fuerte reajuste de los mismos, como consecuencia de los grandes aumentos registrados en el costo de la construcción. Desde la creación del PFV hasta 1977 se dieron en todo el país 201773 créditos de interés social, notándose en los últimos años una declinación de los mismos, sobre todo en el Distrito Federal. 
El crédito hipotecario permite a la empresa promotora pagar la construcción a medida que ésta se realiza, acelerando así la tasa de rotación del capital industrial.

En el caso de los créditos de interés social, que cubren hasta el $80 \%$ del costo de vivienda, el "crédito puente" se entrega al promotor para prefinanciar la construcción, y luego es transferido a los usuarios para financiar el período de circulación de la vivienda.

De esta manera los promotores, mediante la articulación del crédito hipotecario y el pago del enganche de los usuarios, consiguen realizar su operación sin mayores desembolsos de dinero y con una rápida obtención de ganancias.

Si bien la construcción de viviendas con créditos hipotecarios para sectores de altos ingresos permite obtener ganancias más elevadas, ella requiere del promotor mayores inversiones (el crédito cubre sólo el 50\% del costo de la vivienda) y una rotación más lenta del capital.

En cambio, la mayoria de los entrevistados ha expresado que actualmente, después del aumento de los topes para la vivienda de interés social, son más rentables las operaciones de este tipo ya que requieren menos capital y permiten obtener ganancias más rápidamente.

Por otra parte, los entrevistados afirmaron la conveniencia de vender lotes con casa y no lotes solos, ya que en el primer caso el crédito hipotecario cubre también el precio del terreno y permite, en consecuencia, apropiarse más rápidamente de la renta del suelo; en cambio los lotes sin casa se venden sin crédito bancario, y deben ser financiados por el fraccionador (a cinco o siete años, en general) con el consiguiente retardo en la recuperación del capital invertido. Sin embargo, muchas veces no tienen más remedio que vender lotes sin casa, por falta de créditos para la vivienda o por problemas de mercado. En efecto, existen sectores de la población que debido a causas económicas (falta de recursos para acceder a los créditos) o preferencias, se inclinan por autoconstruir la vivienda o producirla por encargo.

En cuanto a la relación entre las empresas promotoras y constructoras sólo en muy pocos casos se ha podido observar que las primeras sean filiales de una constructora relativamente importante, es decir, que el capital de promoción provenga de la industria de la construcción.

En otros casos se ha observado, en cambio, que la promotora ha creado una pequeña constructora, sobre todo para el desarrollo y aplicación de métodos constructivos que permiten acortar el tiempo de la construcción, acelerando así el período de rotación del capital con el consiguiente aumento de la tasa de ganancia.

Los grupos mayores de promoción, por su parte, no incluyen empresas constructoras propias ya que su posición de dominio dentro del sistema les permite, en cierta medida, expoliar a otras empresas constructoras, sobre todo a través de las formas de pago. 
De lo expuesto se puede concluir que el sistema de fraccionamiento en México coexiste y se combina con el de la promoción inmobiliaria, a pesar de que ha tendido a retroceder por el avance de ésta. Es difícil aceptar, como en el caso de países europeos, que se trate de un sistema de transición en la medida que no son los propietarios iniciales de la tierra los que fraccionan, sino empresas capitalistas fraccionadoras, que basan su negocio en la especulación o en la valorización del suelo a través de la urbanización.

Otra conclusión a que ha conducido hasta ahora el análisis, es que el sistema del gran fraccionamiento vinculado a la promoción inmobiliaria, se apoya sobre todo en la valorización de la tierra, con base en la especulación y a la generación de rentas diferenciales.

La forma de adquirir o apropiarse de terrenos periféricos, el desarrollo por etapas de la urbanización, el tamaño y localización de las secciones promovidas, la forma como se combina en el tiempo y el espacio la comercialización de lotes con o sin vivienda, constituyen los instrumentos eficaces de la gran valorización del suelo. Por otra parte, la combinación de un capital de promoción relativamente pequeño, con el capital de crédito (hipotecario y de corto plazo) o el capital desvalorizado del Estado, o con una combinación de ambos, permite a los promotores, con un limitado desembolso inicial y a veces una rápida rotación del capital, obtener una elevada tasa de ganancia. Sin embargo, al completar el análisis sería necesario descubrir más precisamente las lógicas particulares de los diferentes tipos de promotores.

Por otro lado, se podría ya avanzar que la gran dependencia del capital financiero monopólico (los departamentos hipotecarios de los tres bancos más importantes concentran alrededor del $55 \%$ de la captación total de los recursos), en la que se basa la lógica de estas operaciones, ha generado un proceso de monopolización en la promoción por el cual pocas grandes empresas prosperan, absorbiendo en algunos casos a las menores. También es posible afirmar que los controles crecientes ejercidos por el Estado, así como la imposición de obligaciones, ha coadyuvado, en cierta medida, a la acentuación de este proceso de monopolización.

Por último resulta evidente que el desarrollo del sistema de fraccionamiento ha significado una extensión desmedida de la periferia metropolitana, una ocupación irracional del suelo urbano, la incorporación de tierra de carácter público al mercado capitalista, y la marginación de los sectores populares del acceso a una vivienda "mínima necesaria".

\section{La promoción inmobiliaria de conjuntos habitacionales}

Mientras los grandes fraccionamientos en el Estado de México han sido promovidos fundamentalmente por empresas capitalistas, los grandes conjuntos habitacionales realizados en el Distrito Federal, son producto 
de la acción de los principales organismos públicos de vivienda (sobre todo INFONAVit, BANOPSA, FOVi y la Dirección de Habitación Popular del Distrito Federal). En general se construyen en terrenos públicos usando muchas veces fideicomisos, ${ }^{13}$ a través de promociones de las propias instituciones y utilizando tanto créditos de tipo bancario, como públicos y mixtos (combinación de capital bancario y público).

Estos organismos han realizado muchas operaciones de más de 2000 viviendas y algunas de 8000 y hasta 9000 unidades.

En cambio, se ha podido observar a través de la información provista por los bancos, que en las promociones privadas predominan los conjuntos de menos de 300 viviendas, siendo bastante excepcionales aquellas que poseen entre 500 y 1000 unidades. En las entrevistas realizadas a algunos promotores de conjuntos se expresó que la gran cantidad de permisos y autorizaciones que exige el Estado, así como las enormes inversiones que las grandes operaciones requieren, desalientan totalmente a los promotores privados y al capital financiero a llevarlas a cabo.

De manera evidente, la producción de conjuntos habitacionales presenta algunas diferencias importantes en relación al sistema de fraccionamientos. El período de duración de las operaciones es mucho menor (dos años en general) : se realizan en forma mucho más concentrada, con lo cual la división en etapas y las inversiones sucesivas no son posibles. La incidencia del elemento soporte tierra en el conjunto de la operación, así como el manejo del mismo en relación a la formación de la ganancia de promoción, deben diferir del caso de los fraccionamientos. (Aún no se está en condiciones de obtener conclusiones más precisas sobre este punto).

Por otro lado, la promoción de conjuntos habitacionales parece estar, aparentemente, vinculada de manera más directa a las grandes empresas constructoras (en los últimos años ellas han comenzado a desarrollar sus empresas de promoción) y al capital financiero monopólico. Los bancos más importantes, además de sus departamentos de crédito hipotecario han creado, más o menos recientemente, sus departamentos inmobiliarios para la realización de estudios técnicos y el desarrollo de la comercialización y administración inmobiliaria; a pesar de ello no se presentan como pro-

13 En el Derecho Mexicano, el fideicomiso es una figura jurídica en virtud de la cual una persona llamada fideicomitente destina ciertos bienes a un fin lícito de. terminado, encomendando la realización de ese propósito a una institución fiduciaria (el banco). El fideicomiso es entonces un elemento de conexión de ciertos bio nes con fines determinados. El "trust" en su forma estadounidense, es el anteceden. te más cercano del fideicomiso mexicano (Manual del fideicomiso mexicano, Banco Nacional de Obras y Servicios Públicos, 1976.)

El fideicomiso puede adoptar formas distintas y usarse además para fines muy diversos, habiendo servido en muchos casos para realizar operaciones al margen de la ley, evadir impuestos, etc. Los organismos públicos de vivienda han usado con frecuencia el fideicomiso para la utilización de sus terrenos en operaciones habitacionales realizadas con financiación bancaria. 
motores, en la medida que legalmente no pueden ser propietarios de terrenos. Sin embargo, es posible que a través de los fideicomisos las instituciones bancarias puedan proveerse de terrenos y participar como socios en el negocio de la promoción, junto a las grandes empresas constructoras y promotoras que están más vinculadas a ellas.

El papel real de los bancos en la promoción inmobiliaria está aún por investigarse, pero sí se puede afirmar que existe un gran avance de su participación y control dentro del sistema.

El Estado, en cambio, además de su función de control y fijación de obligaciones a través de normas, cargas impositivas, etc., a cuyos posibles efectos sobre la promoción inmobiliaria ya se ha hecho referencia, desarrolla una serie de programas habitacionales, por medio de los cuales se combina y relaciona de diferentes maneras con la empresa privada. Así, a través del financiamiento y la promoción públicas de viviendas el Estado limita la actividad bancaria y la promoción inmobiliaria privada, bloqueando así al capital privado el acceso a un campo donde podría valorizarse. Por el contrario, a través del desarrollo de la obra pública y del financiamiento a promotores privados apoya la expansión de empresas privadas de construcción y promoción, facilitando la valorización de sus capitales. Los efectos contradictorios de la acción del Estado sobre los capitales privados no han impedido la concentración y centralización monopolistas en el sector.

La necesidad de profundizar el análisis de la función real de los bancos en la promoción inmobiliaria, así como el estudio preciso de la vinculación entre el capital privado y la acción pública de vivienda en sus diferentes modalidades de articulación, que surge de estas primeras exploraciones y conclusiones, orientará los estudios que se llevarán a cabo en la siguiente etapa de este proceso de investigación. 